\title{
Prevalence and Risk Factors of Falls Among the Elderly in Unaizah City, Saudi Arabia
}

*Abdullaziz Alabdullgader and Unaib Rabbani

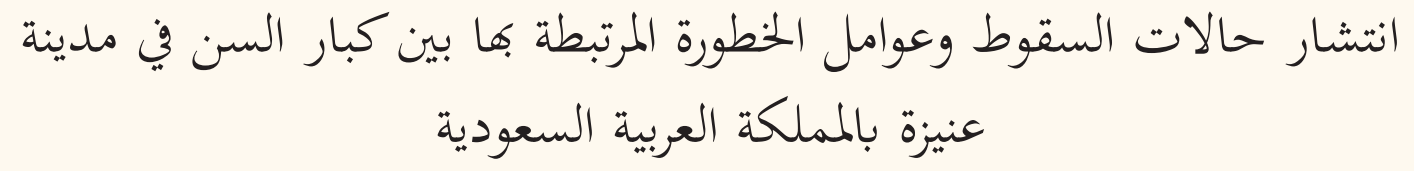

$$
\text { عبد العزيز العبد القادر وأنيب رباني }
$$

ABSTRACT: Objectives: Falls and fall-related consequences are a major public health problem in the elderly. This study aimed to measure the prevalence of falls and fall-related risk factors among elderly individuals in Saudi Arabia. Methods: This cross-sectional study was conducted between January and October 2019 among 280 elderly patients aged >60 years old attending 10 randomly selected primary healthcare centres in Unaizah City, Qassim Province, Saudi Arabia. Data were collected using the validated 10-item Missouri Alliance for Home Care (MAHC-10) fall risk assessment tool. Results: A total of 269 participants were included in the study (response rate: 96.1\%). The prevalence of falls over the preceding year was $31.6 \%$. Females fell more frequently than males (34.5\% versus $28.5 \%$ ) and most falls occurred indoors (84.7\%). Various risk factors were associated with fall risk including being aged $>80$ years (adjusted odds ratio [aOR]: 5.17, 95\% confidence interval [CI]: 1.66-16.14), polypharmacy (aOR: 2.40, 95\% CI: 1.01-5.71) and environmental factors (aOR: 2.79, 95\% CI: 1.24-6.28). However, more educated participants had a lower risk of falling (aOR: 0.26, 95\% CI: 0.09-0.77). There was also a significant association with the MAHC-10 fall risk score $(P=0.043)$. Conclusion: There was a high prevalence of falls among the elderly in Unaizah City. Various factors were associated with falls including advanced age, polypharmacy, age-related changes and environmental factors. As the majority of fall events occurred indoors, home safety improvements are recommended. Moreover, additional larger-scale research is necessary regarding fall-related risk factors and fall prevention initiatives among elderly individuals in Saudi Arabia.

Keywords: Elderly; Falls; Geriatrics; Public Health; Prevalence; Risk Factors; Saudi Arabia.

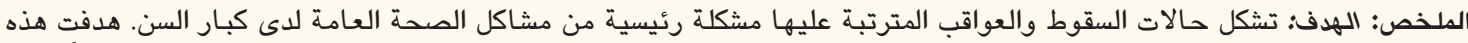

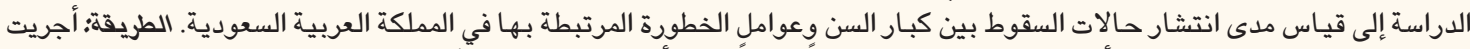

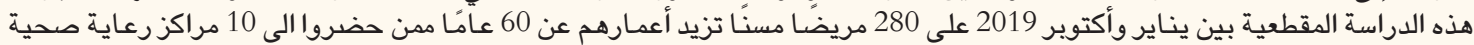

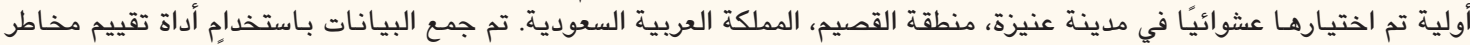

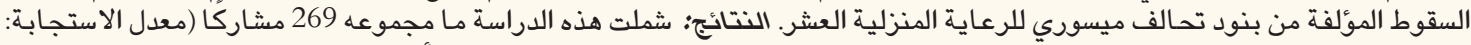

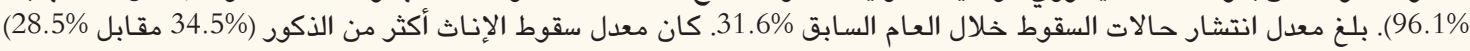

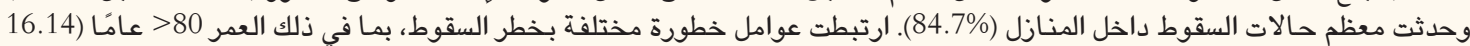

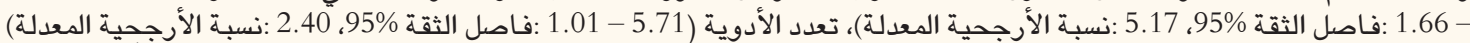

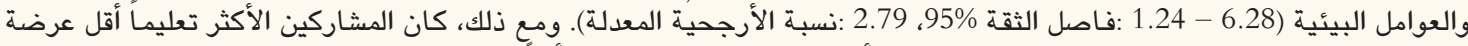

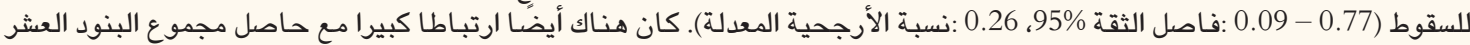

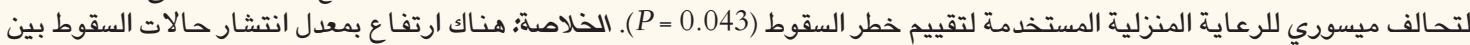

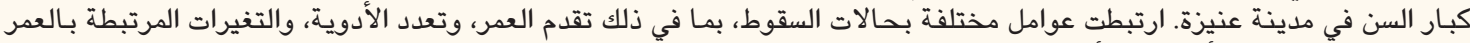

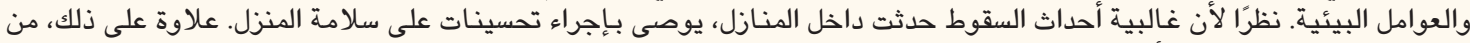

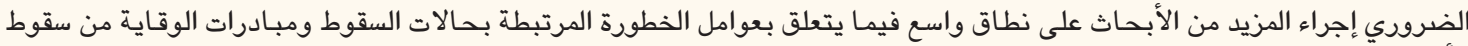

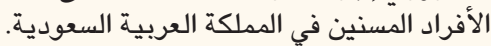

الكلمات المفتاحية؛ كبار السن؛ سقوط؛ طب الشيخوخة؛ الصحة العامة؛ انتشار؛ عوامل الخطورة؛ المملكة العربية السعودية.

\section{Advances in KNOWLEDGE}

This study adds important information to fill the gap in the existing literature regarding the burden of falls among the elderly in the Middle East.

The results indicated that females have a higher prevalence of falls than males and most falls occur indoors.

Age-associated decline in function due to gait changes, visual impairment, memory loss and chronic pain was a significant predictor of falling, as were environmental factors such as high door sills, inadequate lighting and uneven flooring. 


\section{Application to Patient Care}

Due to increasing life expectancy, the proportion of the elderly patient population is growing, resulting in a greater burden of care required for this high-risk group.

Based on this study's findings, targeted health promotion and fall prevention education interventions are needed to ensure healthy ageing and reduce fall-related injuries in Saudi Arabia.

The 10-item Missouri Alliance for Home Care fall risk assessment tool can be used in routine primary care practice to screen elderly patients and identify fall-related predisposing factors. This tool would help inform individualised care and provide targeted health education initiatives to prevent fall-related injuries.

\section{$\mathrm{T}$} HE WORLD HEALTH ORGANIZATION DEFINES a fall as "an event which results in a person coming to rest inadvertently on the ground, floor or other lower level". ${ }^{1}$ In the USA, falls are a leading cause of morbidity and mortality among older adults. ${ }^{2}$ Falls among the elderly can result in a myriad of adverse consequences including disability, loss of independence, decreased daily functioning and increased mortality and fear of falling. ${ }^{3-5}$ In most developed countries, old age is usually defined as beginning from 60 or 65 years, roughly equivalent to the retirement age. ${ }^{6}$ According to the United Nations, 60 years of age is used as a reference point for someone to be described as elderly.

A number of fall-related risk factors among elderly individuals have been reported in the existing literature including age, comorbidities, lack of physical activity and urinary incontinence. ${ }^{1,8}$ Age, gender and race are non-modifiable risk factors. In contrast, modifiable factors include polypharmacy, excessive alcohol consumption, lack of exercise and environmental risks such as poor interior design, insufficient lighting and uneven flooring or surfaces. ${ }^{1}$ While obesity appears to be associated with a greater risk of falling, a body mass index (BMI) of $\geq 40 \mathrm{~kg} / \mathrm{m}^{2}$ may reduce the risk of fall-related injury due to mobility limitations. ${ }^{9}$ Comorbidities such as hypertension (HTN) and diabetes mellitus (DM) also increase the risk of falling, as do impaired balance and visual and gait disorders., ${ }^{2,10,11}$ A review of fall-related risk factors reported that a history of previous falls was also a risk factor among the elderly. ${ }^{12}$ A meta-analysis indicated that falls were most strongly associated with a history of falls, gait problems, use of walking aids, vertigo, Parkinson's disease and antiepileptic drug use. ${ }^{13}$

Various researchers worldwide have studied falls among the elderly. In the USA, the annual prevalence of falls is $22 \% .{ }^{14}$ Other studies from elsewhere have estimated the prevalence of falls each year to be 16.537.4\% worldwide, including Ecuador, Japan, Ethiopia, India and the UK. ${ }^{8,15-19}$ In Canada, a recent study showed that the prevalence of falls in the past one year was $34.5 \%$, while the rate of seeking medical attention for falls was $20.2 \%$ and fear of falling was 38.8\%. ${ }^{20}$ Similarly, other researchers have reported that $26.9 \%$ and $43.3 \%$ of Japanese men and women, respectively, have a fear of falling. ${ }^{21}$ In Italy, Cesari et al. reported that the rate of falls among frail elderly people living in the community was $35.9 \%$, with falls frequently correlated with modifiable factors such as wandering off, gait problems, depression and environmental hazards. ${ }^{22}$

Unfortunately, there is a lack of literature regarding falls among elderly individuals in the Middle East. In the United Arab Emirates (UAE), one study demonstrated that approximately $50 \%$ of elderly participants had experienced a fall incident in the preceding two years, with females and those aged $\geq 70$ years more likely to fall compared to their male and younger counterparts, respectively. ${ }^{23}$ Only two previous studies have sought to assess falls among the elderly in Saudi Arabia. ${ }^{24,25}$ Almegbel et al. found that the yearly prevalence of falling among elderly individuals in Riyadh was 49.9\%, with medications, walking aids, cerebrovascular accidents, poor vision and back pain strongly associated with falls. ${ }^{24}$ In turn, Alshammari et al. reported that $57.7 \%$ of elderly participants in Riyadh had a history of falls, with significant associations noted for advanced age, female gender, impaired health and environmental hazards. ${ }^{25}$

As with other places worldwide, countries in the Middle East are currently experiencing a demographic transition wherein increasing life expectancy is contributing to an increase in the elderly proportion of the population.,26 Estimating the burden and risk factors of falls among older individuals is an important step towards preventing this problem. ${ }^{2,3}$ However, there appears to be a wide variation in the burden of falls due to differences in environmental and populationbased characteristics including specific fall-related risk factors. ${ }^{12}$ Given the paucity of literature regarding falls among the elderly in the Middle Eastern region, the current study aimed to measure the prevalence of falls and fall-related risk factors among elderly individuals in Qassim Province, Saudi Arabia. 


\section{Methods}

This cross-sectional study was conducted between January and October 2019 among elderly patients aged $\geq 60$ years visiting primary healthcare centres ( $\mathrm{PHCs}$ ) in Unaizah City, the second-largest city in Qassim Province with an estimated elderly population of 10,642 ( $6.5 \%$ of the total population). ${ }^{27}$ The necessary sample size was calculated to be 257 participants at a 95\% confidence level with a 5\% bound on error and an expected prevalence of $22 \%{ }^{14}$ The aforementioned local studies were not used for sample size determination due to methodological differences and limitations. ${ }^{24,25}$ To account for attrition and missing data, 28 consecutive elderly patients were recruited from each of the 10 out of 19 PHCs in Unaizah City selected via simple random sampling, resulting in a total of 280 subjects.

Data were collected from the participants using a structured Arabic-language questionnaire developed from a review of the literature. The final version of the questionnaire was reviewed by family and community medicine consultants for face validitythe questionnaire comprised two sections. The first part assessed demographic data (i.e. age, gender, education level, income and smoking status) and the second explored fall prevalence in the prior three and 12 months.

In addition, fall-related risk factors were assessed using the 10-item Missouri Alliance for Home Care (MAHC-10), a standardised, validated tool which explores 10 variables of fall risk including advanced age ( $>65$ years), comorbidities ( $>3$ medical diagnoses), a history of falls within the last three months, incontinence, vision impairment, impaired functional mobility, polypharmacy ( $\geq 4$ concurrent medications), cognitive impairment, chronic pain affecting the level of function (i.e. knee pain) and environmental hazards (i.e. poor illumination, equipment tubing, inappropriate footwear, pets, hard-to-reach items, uneven/cluttered floor surfaces and outdoor entry and exit points) ${ }^{28,29}$ In terms of scoring, each item received a score of one if present and zero if absent, with total scores of $\geq 4$ indicating an increased risk of falling. ${ }^{28}$ As no validated Arabic translation of the MAHC-10 tool was readily available, the principal investigator performed the translation of the original English-language questionnaire. The translated version was subsequently back-translated to English by two independent bilingual translators and then cross-checked with the original version to ensure the accuracy of the translation.

Data were analysed using the Statistical Package for the Social Sciences (SPSS), Version 21.0 (IMB Corp.,
Armonk, New York, USA). Results were presented as frequencies and proportions for categorical variables and means with standard deviations for continuous variables. Univariate and multivariate logistic regression analyses were conducted to assess associations between falls and sociodemographic and other variables. Crude and adjusted odds ratios (aORs) along with 95\% confidence intervals (CIs) were calculated for fall-related risk factors. All variables were included in the univariate logistic regression model. Subsequently, those found to be significant or non-significant but biologically important were included in the multivariate model. Correlations between variables were assessed using Pearson's and Spearman's correlation coefficients and Cramer's V and Phi statistics. If variables were correlated with each other, only one was retained in the regression model. Variables were included in the final model based on associated changes in -2log likelihood ratios. A $P$ value of $<0.050$ was considered statistically significant.

This study was reviewed and approved by the Qassim Regional Bioethics Committee of the Ministry of Health in Saudi Arabia (Approval No.: 1440-1411549). Permission to conduct the study was also sought from the Unaizah Health Sector Office, which oversees the governorate's primary healthcare services. Informed consent was obtained from all elderly individuals prior to their participation in the study.

Table 1: Sociodemographic characteristics of elderly patients attending primary healthcare centres in Unaizah City, Saudi Arabia (N = 269)

$\begin{array}{lc}\text { Characteristic } & \mathbf{n}(\%) \\ \text { Gender } & \\ \text { Male } & 133(49.4) \\ \text { Female } & 136(50.6) \\ \text { Age in years } & \\ 60-69 & 155(57.6) \\ 70-79 & 78(29) \\ \geq 80 & 36(13.4) \\ \text { Education level } & \\ \text { Uneducated } & 104(38.7) \\ \text { Up to middle school } & 98(36.4) \\ \text { High school and above } & 67(24.9) \\ \text { Income in SAR } & \\ <500 & 76(28.3) \\ 500-1,000 & 148(55) \\ >2,000 & 45(16.7) \\ \text { SAR Saudi Arabian Riyal. } & \end{array}$


Table 2: Fall-related risk factors among elderly patients attending primary healthcare centres in Unaizah City, Saudi Arabia $(\mathrm{N}=269)$

\begin{tabular}{|c|c|}
\hline Factor & n (\%) \\
\hline \multicolumn{2}{|l|}{ BMI category } \\
\hline Normal & $70(26)$ \\
\hline Overweight & $116(43.1)$ \\
\hline Obese & $83(30.9)$ \\
\hline \multicolumn{2}{|l|}{ Activity status } \\
\hline Active & 247 (91.8) \\
\hline Inactive & $22(8.2)$ \\
\hline \multicolumn{2}{|l|}{ Regular physical exercise } \\
\hline Yes & $85(31.6)$ \\
\hline No & $184(68.4)$ \\
\hline \multicolumn{2}{|l|}{ Smoking status } \\
\hline Smoker & $23(8.6)$ \\
\hline Non-smoker & 246 (91.4) \\
\hline \multicolumn{2}{|l|}{ Age-related factors* } \\
\hline Gait impairment & $26(9.7)$ \\
\hline Visual impairment & $42(15.6)$ \\
\hline Memory loss & $20(7.4)$ \\
\hline Incontinence & $21(7.8)$ \\
\hline Chronic pain & 32 (11.9) \\
\hline Chronic disease* & $222(82.5)$ \\
\hline HTN & $159(59.1)$ \\
\hline DM & $152(56.5)$ \\
\hline Arthritis & $54(20.1)$ \\
\hline CVA & $21(7.8)$ \\
\hline \multicolumn{2}{|l|}{ Polypharmacy } \\
\hline Yes & $156(58)$ \\
\hline No & $113(42)$ \\
\hline \multicolumn{2}{|l|}{ Environmental factors* } \\
\hline Poor lighting & $26(9.7)$ \\
\hline Inappropriate footwear & $17(6.3)$ \\
\hline Pets & $15(5.6)$ \\
\hline Uneven floor surfaces & $38(14.1)$ \\
\hline High door sills & $51(19)$ \\
\hline
\end{tabular}

\section{Results}

Of the 280 elderly patients recruited for inclusion in the study, 274 (97.9\%) consented to participate;
Table 3: Fall prevalence, location and risk category among elderly patients attending primary healthcare centres in Unaizah City, Saudi Arabia ( $=269)$

\begin{tabular}{|c|c|}
\hline Variable & n (\%) \\
\hline \multicolumn{2}{|l|}{ History of falls } \\
\hline Over the last three months & $23(8.6)$ \\
\hline Over the last year & 85 (31.6) \\
\hline \multicolumn{2}{|l|}{ Location of falls* } \\
\hline Indoors & $72(84.7)$ \\
\hline Bedroom & $12(16.7)$ \\
\hline Washroom & $20(27.8)$ \\
\hline Stairs & $18(25)$ \\
\hline Kitchen & $9(12.5)$ \\
\hline Front doorstep & $11(15.3)$ \\
\hline Other & $2(2.8)$ \\
\hline Outdoors & $13(15.3)$ \\
\hline Masjid $(\mathrm{n}=13)$ & $3(23.1)$ \\
\hline Street $(\mathrm{n}=13)$ & $8(61.5)$ \\
\hline Other $(\mathrm{n}=13)$ & $2(15.4)$ \\
\hline \multicolumn{2}{|l|}{ Fall risk category $^{\dagger}$} \\
\hline At risk & $93(34.6)$ \\
\hline No risk & $176(65.4)$ \\
\hline
\end{tabular}

however, five (1.8\%) were excluded due to incomplete information. As such, a total of 269 participants were included in the final analysis (response rate: 96.1\%). The participants ranged in age from 60-90 years, with a mean age of $70.3 \pm 8.18$ years and $68.6 \pm 6.8$ years for males and females, respectively. The majority (57.6\%) were aged $60-70$ years, while $13.4 \%$ were $\geq 80$ years old. Approximately a quarter (24.9\%) of the participants had been educated to the high school level or higher, whereas $38.7 \%$ were uneducated. A greater number of female participants were uneducated compared to male participants (48.5\% versus $28.6 \%$ ). More than half of the cohort (55\%) received a moderate income of 5,000-1,000 Saudi Arabian riyals [Table 1].

In terms of fall-related risk factors, the prevalence of obesity (i.e. a BMI of $\geq 30 \mathrm{~kg} / \mathrm{m}^{2}$ ) was $30.9 \%$. A total of 22 participants (8.2\%) were inactive. Only $31.6 \%$ regularly performed physical exercise and $8.6 \%$ were smokers. Most participants had chronic diseases, including HTN (20.8\%), DM (18.2\%) or both HTN and DM (38.2\%). Polypharmacy was prevalent in 58\% of the cohort and $11.2 \%$ used ambulatory aids. Visual 
Table 4: Risk factors associated with falls and fall risk score among elderly patients attending primary healthcare centres in Unaizah City, Saudi Arabia ( $=269)$

\begin{tabular}{|c|c|c|c|c|}
\hline Variable & $\begin{array}{l}\text { Unadjusted OR } \\
\quad(95 \% \mathrm{CI})\end{array}$ & $P$ value & $\begin{array}{l}\text { Adjusted OR ( } 95 \% \\
\text { CI) }\end{array}$ & $P$ value \\
\hline \multicolumn{5}{|l|}{ Age in years } \\
\hline $60-69$ & 1 & - & 1 & - \\
\hline $70-79$ & $3.5(1.91-6.42)$ & $<0.001$ & $1.61(0.70-3.69)$ & 0.259 \\
\hline$\geq 80$ & $8.02(3.62-17.74)$ & $<0.001$ & $5.17(1.66-16.14)$ & 0.005 \\
\hline \multicolumn{5}{|l|}{ Education level } \\
\hline Uneducated & 1 & - & 1 & - \\
\hline Up to middle school & $0.39(0.21-0.70)$ & 0.002 & $0.46(0.20-1.03)$ & 0.060 \\
\hline High school and above & $0.16(0.07-0.37)$ & $<0.001$ & $0.26(0.09-0.77)$ & 0.015 \\
\hline BMI category & $9(12.5)$ & & & \\
\hline Normal & 1 & - & 1 & - \\
\hline Overweight & $1.39(0.70-2.78)$ & 0.337 & $1.47(0.57-3.80)$ & 0.419 \\
\hline Obese & $2.46(1.21-4.99)$ & 0.013 & $2.32(0.86-6.31)$ & 0.096 \\
\hline \multicolumn{5}{|l|}{ Polypharmacy } \\
\hline No & 1 & - & 1 & - \\
\hline Yes & $5.03(2.89-8.77)$ & $<0.001$ & $2.40(1.01-5.71)$ & 0.046 \\
\hline \multicolumn{5}{|l|}{ Age-related changes } \\
\hline No & 1 & - & 1 & - \\
\hline Yes & $11.08(6.07-20.22)$ & $<0.001$ & $2.77(1.14-6.73)$ & 0.024 \\
\hline \multicolumn{5}{|l|}{ Environmental factors } \\
\hline Absent & 1 & - & 1 & - \\
\hline Present & $4.72(2.64-8.44)$ & $<0.001$ & $2.79(1.24-6.28)$ & 0.013 \\
\hline \multicolumn{5}{|l|}{ Fall risk category* } \\
\hline No risk & 1 & - & 1 & - \\
\hline At risk & $16.28(8.65-30.66)$ & $<0.001$ & $3.07(1.03-9.10)$ & 0.043 \\
\hline
\end{tabular}

$O R=$ odds ratio; $C I=$ confidence interval; $B M I=$ body mass index. *Based on scores from the validated 10-item Missouri Alliance for Home Care fall risk assessment tool. ${ }^{28,29}$ Scores of $\geq 4$ were considered to indicate risk of falling. ${ }^{28}$

impairment, gait problems, memory loss, incontinence and chronic pain were reported in $15.6 \%, 9.7 \%, 7.4 \%$, $7.8 \%$ and $11.9 \%$ of participants, respectively. At least one environmental risk factor was present in $52 \%$ of the cohort, with the most frequent hazards being high door sills (19\%), uneven floor surfaces (14.1\%) and poor lighting (9.7\%) [Table 2].

The prevalence of falls over the preceding year was $31.6 \%$, with a higher rate of falls among females than males (34.5\% versus $28.5 \%$ ). The three-month prevalence of falls was $8.6 \%$. Of the 85 participants who had fallen during the preceding year, $84.7 \%$ had fallen indoors, with the most frequent locations being in washrooms $(27.8 \%)$ and on stairs (25\%). Outdoor falls occurred among $15.3 \%$ of those with a history of falls over the last 12 months, most of which happened on the street (61.5\%). A total of 93 participants (34.6\%) were categorised as being at high risk of falling based on their MAHC-10 fall risk scores [Table 3]. Of these, 64 (68.8\%) had fallen during the preceding year, with a significant association between fall risk score and history of falls $(P<0.001)$.

According to the multivariate logistic regression analysis, there was a strong association between advanced age and fall risk; individuals aged $\geq 80$ years were five times more at risk of falling compared to younger participants (aOR: 5.17, 95\% CI: 1.66-16.14; $P$ $=0.005$ ). Polypharmacy (aOR: 2.40, 95\% CI: 1.01-5.71; $P=0.046$ ), age-related changes (aOR: $2.77,95 \% \mathrm{CI}$ : 1.14-6.73; $P=0.024$ ) and environmental factors (aOR: 2.79, 95\% CI: 1.24-6.28; $P=0.013$ ) also significantly increased falling risk, particularly poor lighting, 
uneven floor surfaces and high door sills. In addition, participants categorised as being at risk of falling based on their MAHC-10 scores were at three times greater risk than those in the no-risk group (aOR: 3.07, 95\% CI: 1.03-9.10; $P=0.043)$. Educated participants were at less risk of falling compared to those who were uneducated (aOR: 0.26, 95\% CI: 0.09-0.77; $P=0.015$ ). Other factors such as obesity, inappropriate footwear and having pets were not related to falling risk [Table 4].

\section{Discussion}

The current study aimed to assess the prevalence of falls and fall-related risk factors among elderly individuals in a Saudi Arabian province. The prevalence of falls over the preceding year in this population group was $31.5 \%$, a rate much higher than those reported from the USA and Japan (22\% and $16.5 \%$, respectively). ${ }^{14,15}$ Similarly, studies from Ecuador, Ethiopia and the UK have also indicated slightly lower rates of falls among the elderly (30.3\%, 28\% and $28 \%$, respectively). ${ }^{8,16,18}$ On the other hand, local research has indicated much higher prevalence rates of falls among the elderly according to two previous studies conducted in Riyadh (49.9\% and 57.7\%)..$^{24,25}$

There are several reasons which could potentially explain these differences in fall prevalence rates across studies. For example, it is possible that the lower prevalence of falls in the current study compared to other studies from Saudi Arabia may be attributed to differences in lifestyle factors, while the higher burden of falls compared to international studies could be due to the influence of comorbid conditions and polypharmacy, both of which are known to increase the risk of falling. ${ }^{8,24}$ Indeed, the prevalence of comorbidities and polypharmacy was lower in the cohorts from Ecuador and the UK, while medication use was higher among participants from one of the studies from Riyadh. ${ }^{8,18,24}$ Additionally, differences in environmental conditions may also contribute to differences in fall prevalence across different settings. ${ }^{12,13}$

In the present study, the prevalence of falls was higher among elderly women compared to elderly men (34.5\% versus $28.5 \%$ ); this is in accordance with findings reported by a similar study from the UK which indicated that the overall ratio of male to female fallers was 1:2.7. ${ }^{19}$ This could be due to fact that there were more uneducated female than uneducated male participants (48.5\% versus $28.6 \%$ ), with educated participants being at significantly less risk of falling compared to those who were uneducated. A study from the UAE also found a higher proportion of fall events among illiterate individuals and those with lower education levels. ${ }^{23}$
In addition, age has consistently been reported to be a risk factor for falling. ${ }^{15,24,25}$ There was a strong association between advanced age and fall risk in the present study, with those aged 80 years or more being five times more likely to fall compared to younger individuals. This can be attributed to an age-induced decline in physical, sensory and cognitive function, as well as an increase in the number of comorbid conditions. Indeed, age-related factors in the current study such as gait, visual impairment, memory loss, incontinence and chronic pain affecting the level of function (e.g. knee pain) were found to increase fall risk by more than two. This is similar to previous local findings. Almegbel et al. reported that elderly individuals living in Riyadh who had good vision were less likely to experience falls than those with poor vision. ${ }^{24}$

While all classes of obesity (BMI of $\geq 30 \mathrm{~kg} / \mathrm{m}^{2}$ ) have been shown to be associated with increased risk of falling, class III obesity (BMI of $\geq 40 \mathrm{~kg} / \mathrm{m}^{2}$ ) has been found to result in a lower risk of fall-related injury. ${ }^{18}$ However, no significant association was observed between fall risk and BMI category in the current study. This may be due to the use of a single category of obesity (BMI $\geq 30 \mathrm{~kg} / \mathrm{m}^{2}$ ) instead of subclasses to avoid insufficient numbers for the statistical analysis. However, polypharmacy (defined as $\geq 4$ concurrent medications) was prevalent in $58 \%$ of the cohort and was found to double the risk of falling. This is similar to findings from a previous study from Riyadh, which reported that the lack of medications was significantly related to fewer falls. ${ }^{24}$

The link between polypharmacy and fall risk could be due to the presence of multiple comorbidities leading to the use of a greater number of medications. Alternatively, both comorbidities and multiple medications could result in fall events because of general poor health and drug-drug interactions or drug-related side-effects, respectively. A significant correlation (0.81) was observed in the present study between the number of comorbidities and number of medications (data not shown). Such findings have important implications for clinical practice. Firstly, healthcare providers must assess all elderly patients' medication history to confirm whether these medications are prescribed or are over-the-counter (OTC) to inform patients regarding the appropriate use and possible side effects of OTC medications. Secondly, healthcare providers should counsel elderly patients taking multiple medications and their family members to take extra care to prevent falls. Medication consultation practices have been found to be an effective method of reducing falls among the elderly. ${ }^{30}$ 
The majority of falls in the current study were found to occur indoors (84.7\%), most frequently in the washroom, stairs and bedroom $(27.8 \%, 25 \%$ and $16.7 \%$, respectively). A previous study conducted by Alshammari et al. in Riyadh also reported that most falls occurred at home $(72.8 \%)$ with the most frequent location being the bathroom (35.7\%). ${ }^{25}$ In turn, the present study found that environmental factors were strongly associated with fall risk, particularly poor lighting, uneven floor surfaces and high door sills; however, inappropriate footwear and the presence of pets were not significantly related. Lim and Sung revealed that poor night lighting and protruding door sills were predictors of accidental falls among older women in South Korea, along with physical inactivity. ${ }^{31}$ Finally, MAHC-10 fall risk score was significantly linked with an increased risk of falling in the current study. A previous Saudi Arabian study also showed a significant association between documented history of falls and MAHC-10 fall risk score. ${ }^{25}$

Certain limitations should be considered when interpreting the results of the present study. First, due to the cross-sectional study design, temporal relationships could not be established. Second, the study targeted patients attending a random selection of PHCs in Unaizah City who may have had chronic diseases and other illnesses; thus, the findings may not be representative of the general population. Third, because of time and resource constraints, the questionnaire could not be pilot-tested to ensure its reliability; however, the translated version was reviewed for face validity. An internationally validated tool was used to assess fall risk factors. ${ }^{28,29}$ Fourth, the true prevalence of falls may have been underreported by the participants, especially as memory impairment is a common concern among elderly people. ${ }^{32,33}$ Finally, the necessary sample size for the study was powered for prevalence alone; as such, the sample size may not have been adequate for determining associations with fall risk.

\section{Conclusion}

This study found a high prevalence of falls among elderly patients attending PHCs in Unaizah City. Most of the falls occurred indoors, thereby highlighting the need for improvements in home design and safety. In addition, various factors were found to be significantly associated with risk of falling including advanced age, polypharmacy, age-related changes and environmental factors. Healthcare providers should screen elderly patients for these risk factors and provide targeted advice and care to prevent falls. Additional research conducted on a larger scale is recommended to further evaluate fall-related risk factors and fall prevention strategies among elderly individuals residing in Saudi Arabia.

\section{CONFLICT OF INTEREST}

The authors declare no conflicts of interest.

\section{FUNDING}

No funding was received for this study.

\section{References}

1. World Health Organization. WHO global report on falls prevention in older age. From: www.who.int/ageing/publications/Falls_prevention7March.pdf Accessed: Jul 2020.

2. Rubenstein LZ. Falls in older people: Epidemiology, risk factors and strategies for prevention. Age Ageing 2006; 35:ii37-41. https://doi.org/10.1093/ageing/afl084.

3. Oliver D. Development of services for older patients with falls and fractures in England: Successes, failures, lessons and controversies. Arch Gerontol Geriatr 2009; 49:S7-12. https:// doi.org/10.1016/S0167-4943(09)70005-6.

4. Sekaran NK, Choi H, Hayward RA, Langa KM. Fall-associated difficulty with activities of daily living in functionally independent individuals aged 65 to 69 in the United States: A cohort study. J Am Geriatr Soc 2013; 61:96-100. https://doi.org/10.1111/ jgs.12071.

5. Stel VS, Smit JH, Pluijm SM, Lips P. Consequences of falling in older men and women and risk factors for health service use and functional decline. Age Ageing 2004; 33:58-65. https://doi. org/10.1093/ageing/afh028.

6. Gorman M. Development and the rights of older people. In: Randel J, German T, Eds. The Ageing and Development Report: Poverty, independence and the world's older people. 1sted.Routledge,1999.Pp.3-21.https://doi.org/10.4324/978131 5071541

7. United Nations Population Fund. Ageing in the twenty-first century: A celebration and a challenge. From: www.unfpa.org/ public/home/publications/pid/11584 Accessed: Jul 2020.

8. Orces $\mathrm{CH}$. Prevalence and determinants of falls among older adults in Ecuador: An analysis of the SABE I Survey. Curr Gerontol Geriatr Res 2013; 2013: 495468. https://doi. org/10.1155/2013/495468.

9. Himes CL, Reynolds SL. Effect of obesity on falls, injury, and disability. J Am Geriatr Soc 2012; 60:124-9. https://doi. org/10.1111/j.1532-5415.2011.03767.x.

10. Maurer MS, Burcham J, Cheng H. Diabetes mellitus is associated with an increased risk of falls in elderly residents of a long-term care facility. J Gerontol A Biol Sci Med Sci 2005; 60:1157-62. https://doi.org/10.1093/gerona/60.9.1157.

11. Vestergaard P, Rejnmark L, Mosekilde L. Hypertension is a risk factor for fractures. Calcif Tissue Int 2009; 84:103-11. https:// doi.org/10.1007/s00223-008-9198-2.

12. Ambrose AF, Paul G, Hausdorff JM. Risk factors for falls among older adults: A review of the literature. Maturitas 2013;75:51-61. https://doi.org/10.1016/j.maturitas.2013.02.009.

13. Deandrea S, Lucenteforte E, Bravi F, Foschi R, La Vecchia C, Negri E. Risk factors for falls in community-dwelling older people: A systematic review and meta-analysis. Epidemiology 2010;21:658-68.https://doi.org/10.1097/EDE.0b013e3181e89905. 
14. Stevens JA, Ballesteros MF, Mack KA, Rudd RA, DeCaro E, Adler G. Gender differences in seeking care for falls in the aged Medicare population. Am J Prev Med 2012; 43:59-62. https:// doi.org/10.1016/j.amepre.2012.03.008

15. Niino N, Tsuzuku S, Ando F, Shimokata H. Frequencies and circumstances of falls in the National Institute for Longevity Sciences, Longitudinal Study of Aging (NILS-LSA). J Epidemiol 2000; 10:S90-4. https://doi.org/10.2188/jea.10.1sup_90.

16. Janakiraman B, Temesgen MH, Jember G, Gelaw AY, Gebremeskel BF, Ravichandran $\mathrm{H}$, et al. Falls among community-dwelling older adults in Ethiopia: A preliminary cross-sectional study. PLoS One 2019; 14:e0221875. https://doi.org/10.1371/journal. pone. 0221875

17. Joseph A, Kumar D, Bagavandas M. A review of epidemiology of fall among elderly in India. Indian J Community Med 2019; 44:166-8. https://doi.org/10.4103/ijcm.IJCM_201_18.

18. Gale CR, Cooper C, Sayer AA. Prevalence and risk factors for falls in older men and women: The English Longitudinal Study of Ageing. Age Ageing 2016; 45:789-94. https://doi.org/10.1093/ ageing/afw129.

19. Blake AJ, Morgan K, Bendall MJ, Dallosso H, Ebrahim SB, Arie $\mathrm{TH}$, et al. Falls by elderly people at home: Prevalence and associated factors. Age Ageing 1988; 17:365-72. https://doi. org/10.1093/ageing/17.6.365

20. Pirrie M, Saini G, Angeles R, Marzanek F, Parascandalo J, Agarwal G. Risk of falls and fear of falling in older adults residing in public housing in Ontario, Canada: Findings from a multisite observational study. BMC Geriatr 2020; 20:11. https:// doi.org/10.1186/s12877-019-1399-1.

21. Tomita Y, Arima K, Tsujimoto R, Kawashiri SY, Nishimura T, Mizukami S, et al. Prevalence of fear of falling and associated factors among Japanese community-dwelling older adults. Medicine (Baltimore) 2018; 97:e9721. https://doi.org/10.1097/ MD.0000000000009721.

22. Cesari M, Landi F, Torre S, Onder G, Lattanzio F, Bernabei R. Prevalence and risk factors for falls in an older communitydwelling population. J Gerontol A Biol Sci Med Sci 2002; 57:M722-6. https://doi.org/10.1093/gerona/57.11.m722.

23. Sharif SI, Al-Harbi AB, Al-Shihabi AM, Al-Daour DS, Sharif RS. Falls in the elderly: Assessment of prevalence and risk factors. Pharm Pract (Granada) 2018; 16:1206. https://doi. org/10.18549/PharmPract.2018.03.1206.
24. Almegbel FY, Alotaibi IM, Alhusain FA, Masuadi EM, Al Sulami SL, Aloushan AF, et al. Period prevalence, risk factors and consequent injuries of falling among the Saudi elderly living in Riyadh, Saudi Arabia: A cross-sectional study. BMJ Open 2018; 8:e019063. https://doi.org/10.1136/bmjopen-2017-019063.

25. Alshammari SA, Alhassan AM, Aldawsari MA, Bazuhair FO, Alotaibi FK, Aldakhil AA, et al. Falls among elderly and its relation with their health problems and surrounding environmental factors in Riyadh. J Fam Community Med 2018;25:29-34. https://doi.org/10.4103/jfcm.JFCM_48_17.

26. Hajjar RR, Atli T, Al-Mandhari Z, Oudrhiri M, Balducci L, Silbermann M. Prevalence of aging population in the Middle East and its implications on cancer incidence and care. Ann Oncol 2013; 24:vii11-24. https://doi.org/10.1093/annonc/mdt268.

27. Saudi Arabia General Authority for Statistics. Sixteenth services guide 2017: Qassim region. From: www.stats.gov.sa/ sites/default/files/al-qaseem_region_ar.pdf Accessed: Jul 2020.

28. Missouri Alliance for Home Care. MAHC 10: Fall risk assessment tool. From: www.homecaremissouri.org/projects/falls/docume nts/Oct2012FINALValidatedFallriskassessmenttool.pdf Accessed: Jul 2020

29. Calys M, Gagnon K, Jernigan S. A validation study of the Missouri Alliance for Home Care fall risk assessment tool. Home Health Care Manag Pract 2013; 25:39-44. https://doi. org/10.1177/1084822312457942.

30. Blalock SJ, Casteel C, Roth MT, Ferreri S, Demby KB, Shankar V. Impact of enhanced pharmacologic care on the prevention of falls: A randomised controlled trial. Am J Geriatr Pharmacother 2010; 8:428-40. https://doi.org/10.1016/j.amjop harm.2010.09.002.

31. Lim YM, Sung MH. Home environmental and health-related factors among home fallers and recurrent fallers in community dwelling older Korean women. Int J Nurs Pract 2012; 18:481-8. https://doi.org/10.1111/j.1440-172X.2012.02060.x.

32. Barker A, Jones R, Jennison C. A prevalence study of ageassociated memory impairment. Br J Psychiatry 1995; 167:642-8. https://doi.org/10.1192/bjp.167.5.642.

33. Larrabee GJ, Crook TH 3rd. Estimated prevalence of ageassociated memory impairment derived from standardised tests of memory function. Int Psychogeriatr 1994; 6:95-104. https://doi.org/10.1017/s1041610294001663. 